Supporting Information for:

\title{
Guest Sequence Can Influence RNA Encapsulation by an Engineered Cationic Protein Capsid
}

Jiannan Fu and Kenneth J. Woycechowsky*

School of Pharmaceutical Science and Technology, Tianjin University, 300072

Tianjin, China

*E-mail: kenneth@tju.edu.cn. Address: 92 Weijin Road, Nankai District, Tianjin, 300072, China. Phone: +86-22-87401830. 


\section{Supplementary Figures}

\section{Figure S1}
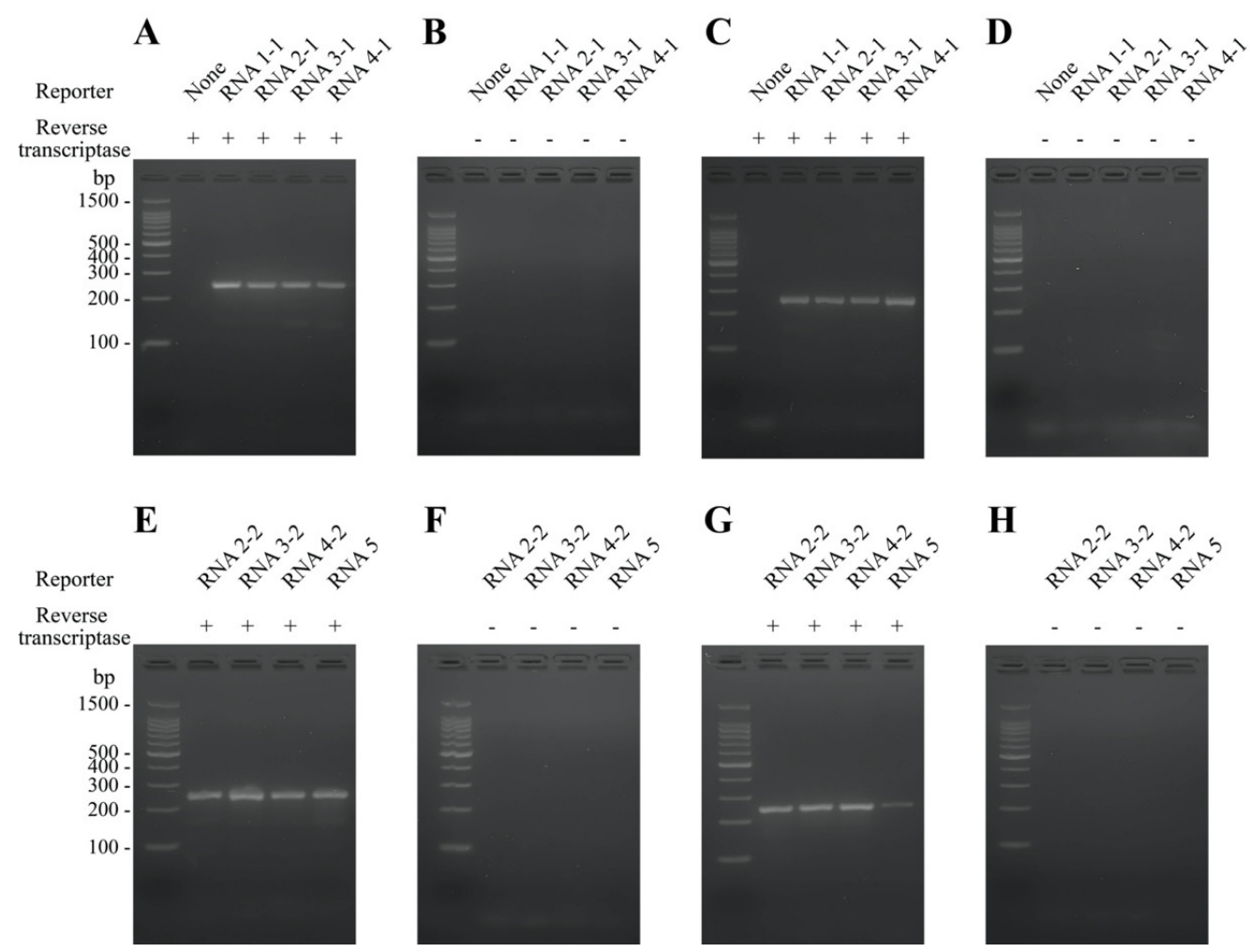

Figure S1. Detection of reporter RNA in RNA extracts from purified AaLS-pos capsids and whole cells. A) Agarose gel electrophoresis of RT-PCR products generated using primers corresponding to the reporter RNA templates extracted from purified AaLSpos capsids that had been co-produced with reporter RNA 1-1, 2-1, 3-1, or 4-1 (as well as AaLS-pos that was produced in the absence of any reporter RNA, as a control). B) Similar to panel A, but without reverse transcription. C) Similar to panel A, but with RNA templates extracted from whole cells. D) Similar to panel B, but with RNA extracted from whole cells. E and F) Similar to panels A and B, respectively, but with RNA templates extracted from AaLS-pos co-produced with reporter RNAs 2-2, 3-2, 4 2, or 5. G and H) Similar to panels $\mathrm{C}$ and D, respectively, but with RNA templates extracted from whole cells that had been co-produced AaLS-pos and reporter RNA 22, 3-2, 4-2, or 5. The leftmost lane in each panel contains DNA size markers. The length of each marker (in bp) is indicated at the left side of panels A and E. 
Figure S2

A

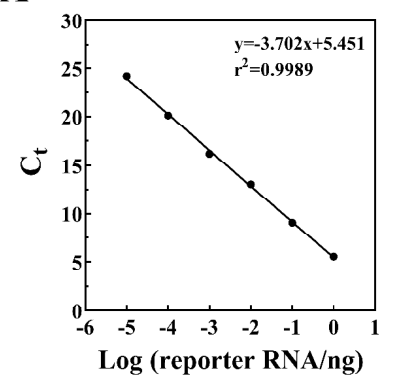

D

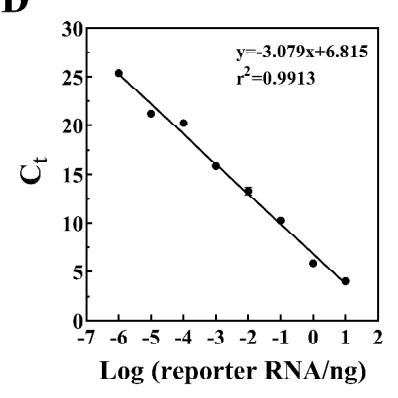

B

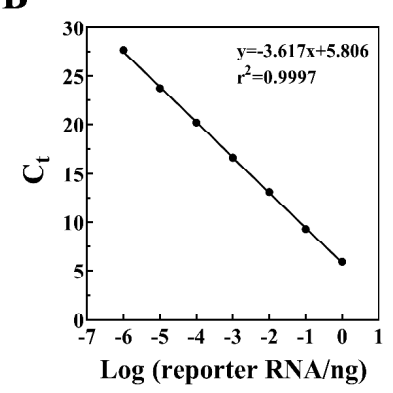

$\mathbf{E}$

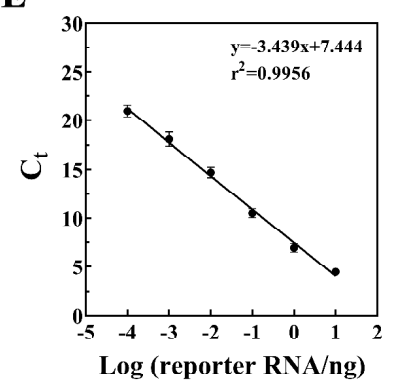

C

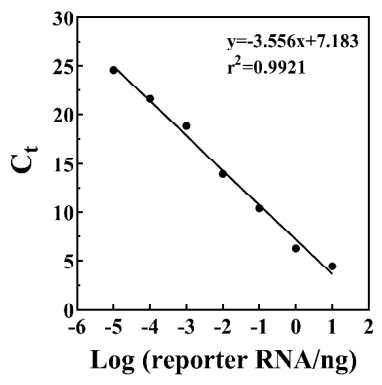

Figure S2. Standard curves for q-RT-PCR analysis of reporter RNAs. A) Reporter RNA 1-1. B) Reporter RNA 2-1 and reporter RNA 2-2. C) Reporter RNA 3-1 and reporter RNA 3-2. D) Reporter RNA 4-1 and reporter RNA 4-2. E) Reporter RNA 5. All of the standard curves were generated using in vitro transcribed RNA templates. The equations and $\mathrm{r}^{2}$ values for the data fitting are given in each graph. 


\section{Figure S3}

A

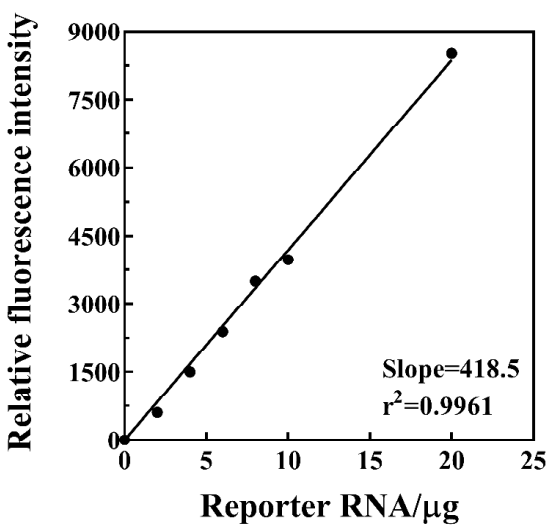

C

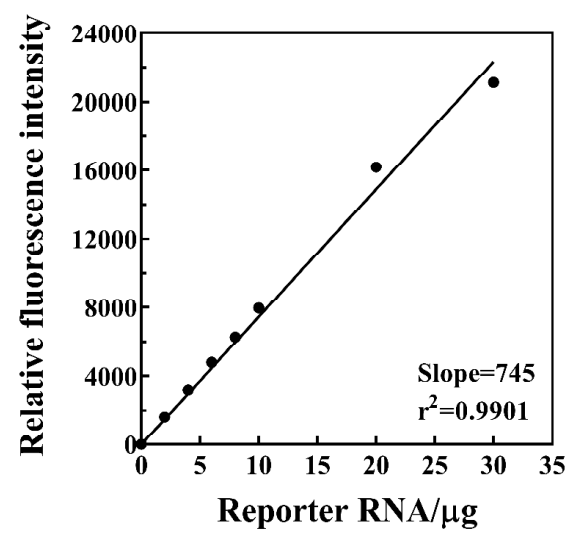

B

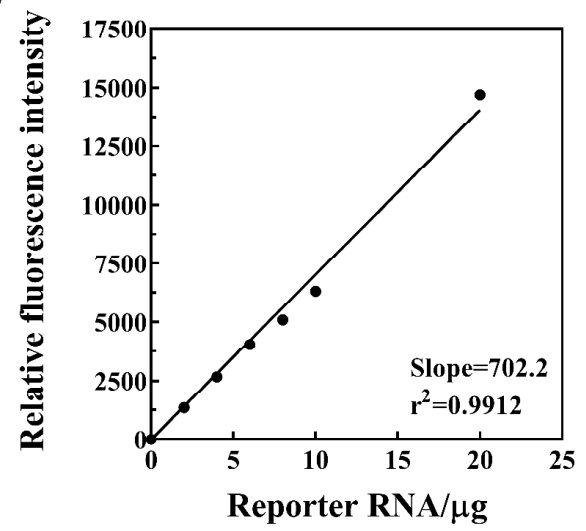

D

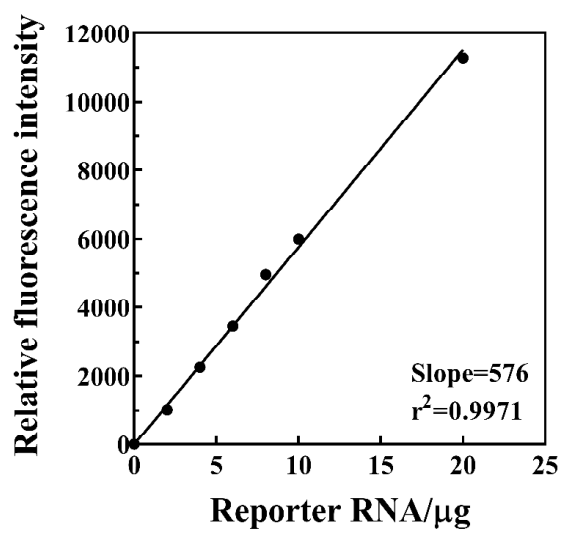

Figure S3. Standard curves for fluorescence analysis of the reporter RNAs that contain the Broccoli-F30 aptamer. A) Reporter RNA 1-1. B) Reporter RNA 2-1. C) Reporter RNA 3-1. D) Reporter RNA 4-1. All of the standard curves were generated using in vitro transcribed RNA templates. The slopes and $\mathrm{r}^{2}$ values for the data fitting are given in each graph. 


\section{Figure S4}

A
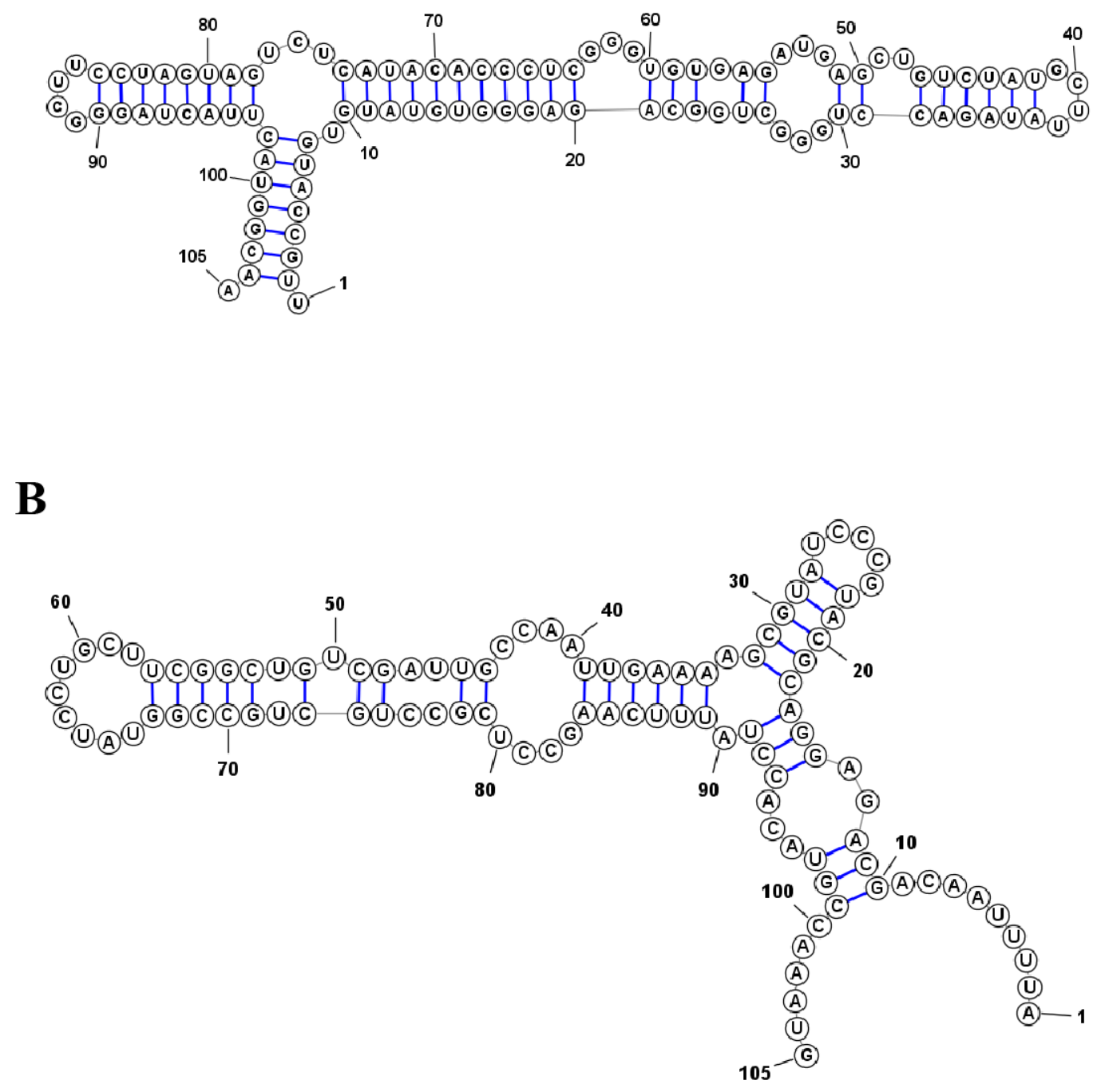

Figure S4. The predicted secondary structures of the Broccoli-F30 aptamer (A) and ASR 6 (B). Secondary structure calculations were made using the mfold web server (http://unafold.rna.albany.edu/?q=mfold). ${ }^{l}$ 
Figure S5

A

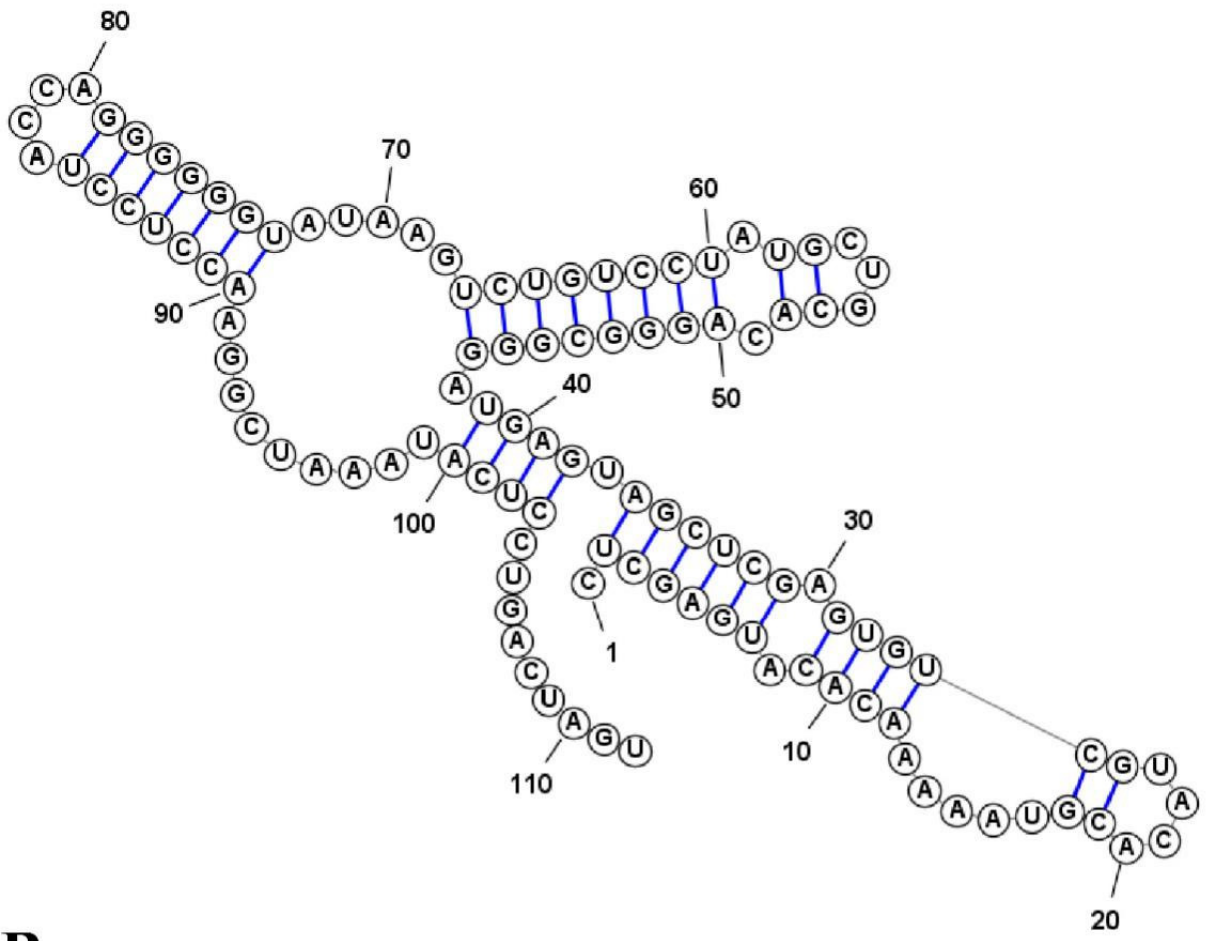

B

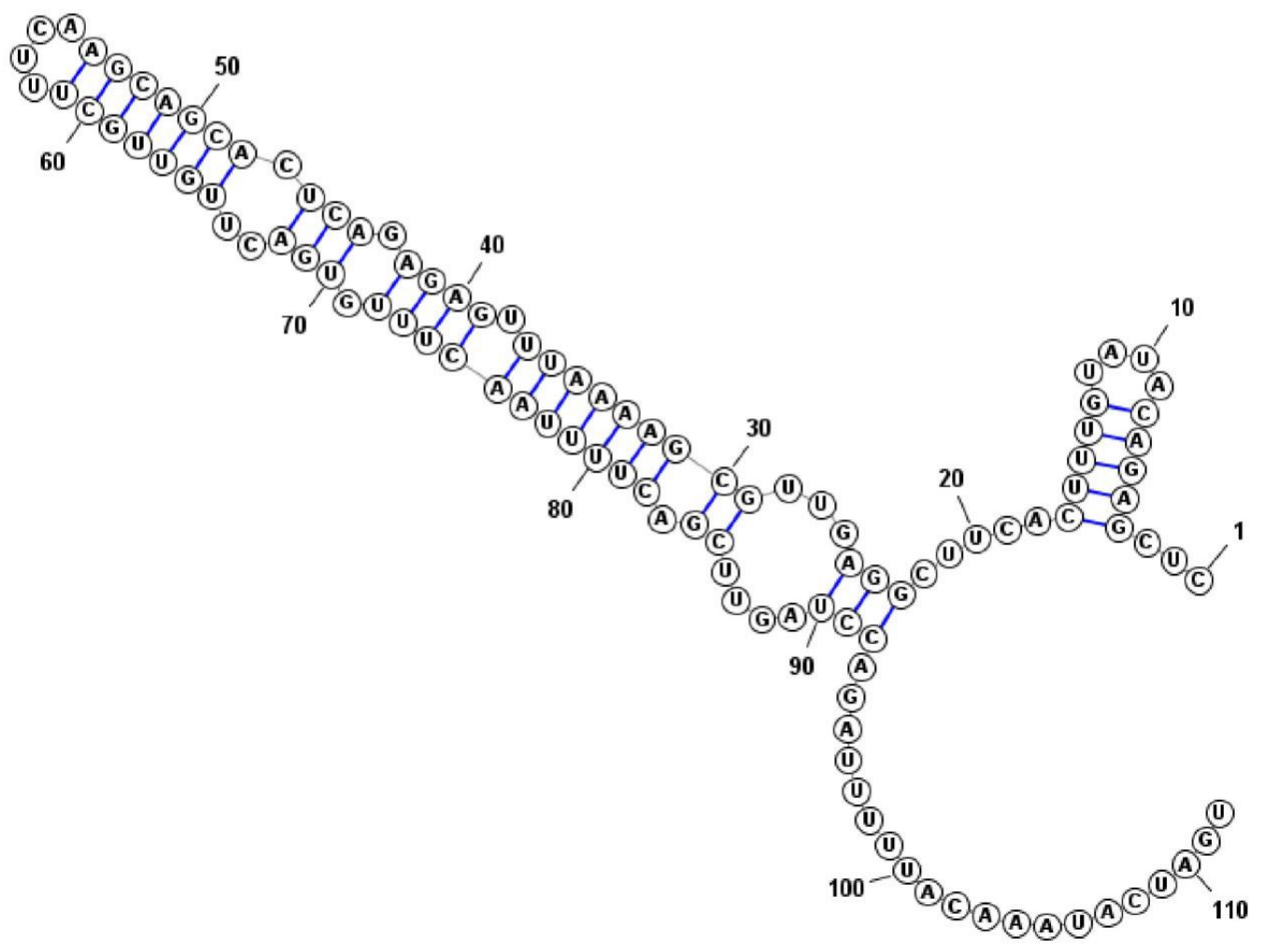

Figure S5 continues on the next page. 
Figure S5 (continued from the previous page)

C

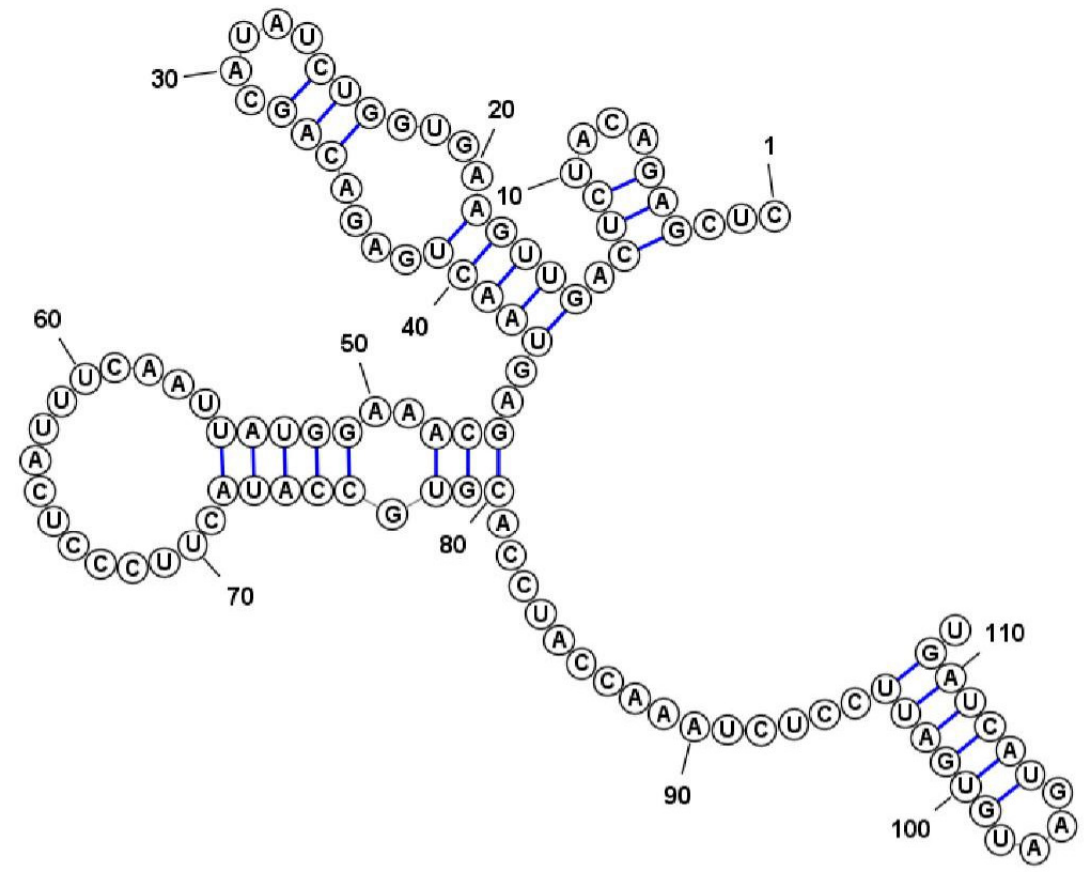

\section{D}

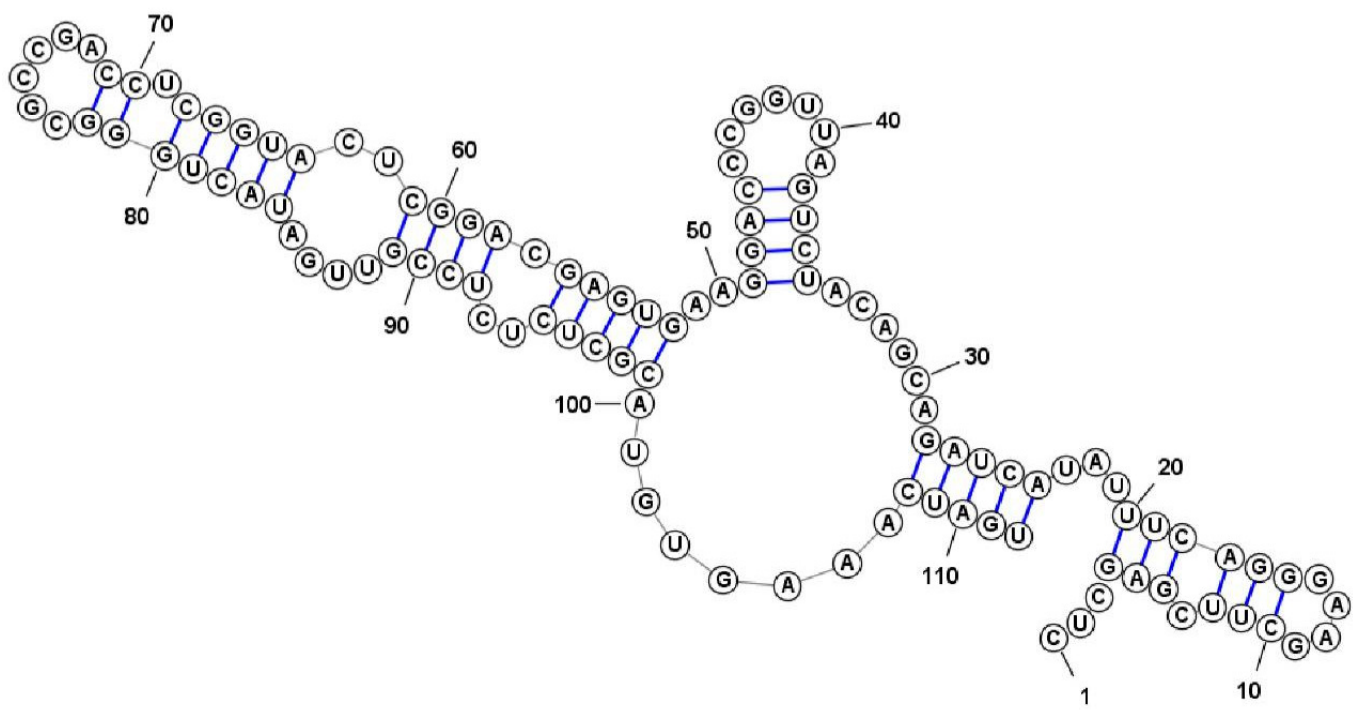

Figure S5 continues on the next page. 
Figure S5 (continued from the previous page)

$\mathbf{E}$

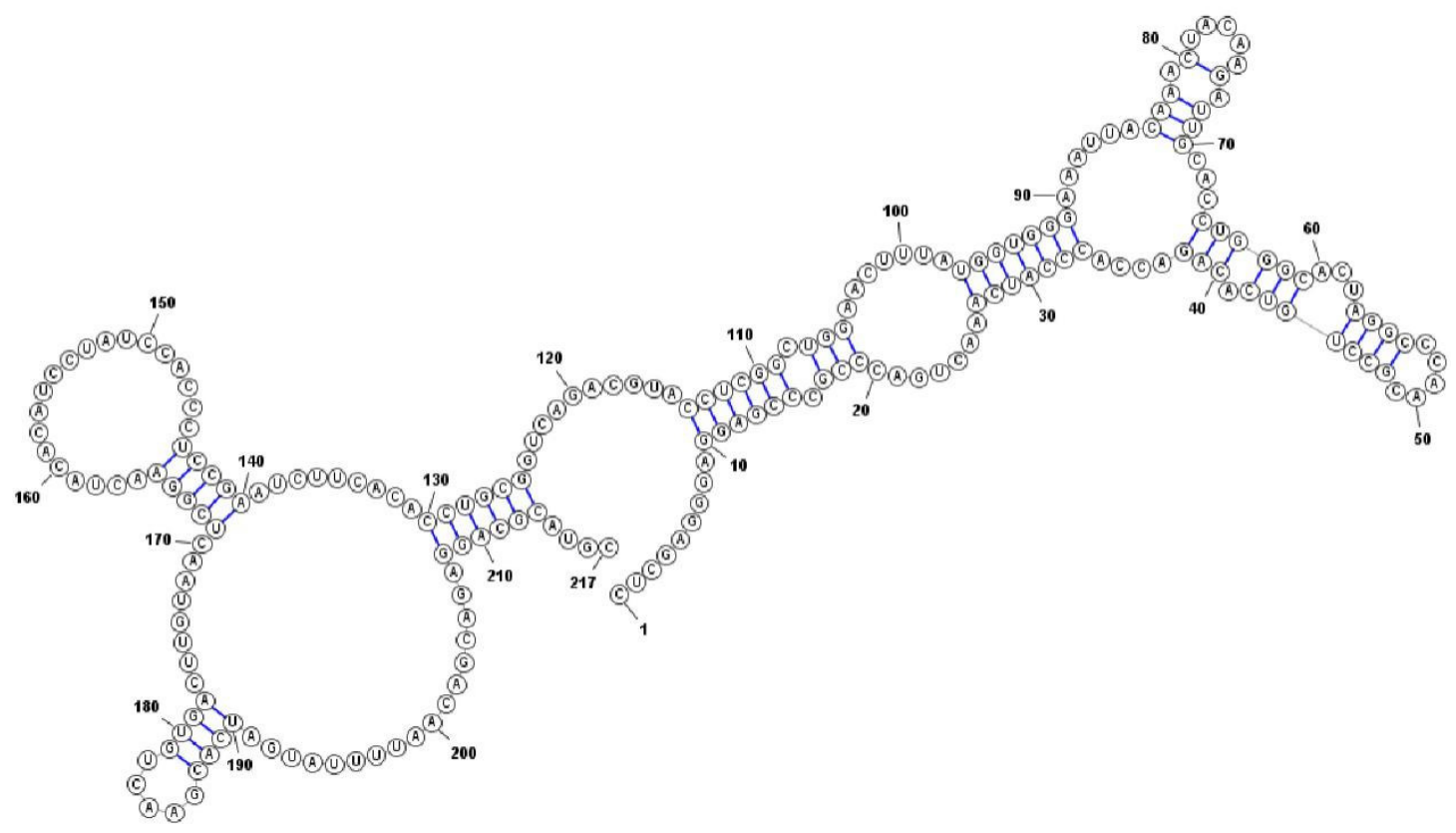

Figure S5. The predicted secondary structures of arbitrary sequence regions. A) ASR 1. B) ASR 2. C) ASR 3. D) ASR 4. E) ASR 5. Secondary structure calculations were made using the mfold web server (http://unafold.rna.albany.edu/?q=mfold). ${ }^{l}$ 


\section{Supplementary Tables}

Table S1. Reporter RNA sequences.

\begin{tabular}{|c|c|}
\hline Name & Nucleotide sequence $\left(5^{\prime} \rightarrow 3^{\prime}\right)^{\mathrm{a}}$ \\
\hline RNA 1-1 & $\begin{array}{l}\text { GGGGAACUCGAGUACACAAAAAUGCACAUGCUGUGAGCUCGAUGAGUA } \\
\text { GGGCGGGACACGUCGUAUCCUGUCUGAAUAUGGGGGGACCAUCCUCCA } \\
\text { AGGCUAAAUACUCCUGACUAGUUUGCCAUGUGUAUGUGGGAGACGGUC } \\
\text { GGGUCCAGAUAUUCGUAUCUGUCGAGUAGAGUGUGGGCUCCCACAUAC } \\
\text { UCUGAUGAUCCUUCGGGAUCAUUCAUGGCAACAUAUGCCGCUGAGCAA } \\
\text { UAACUAGCAUAACCCCUUGGGGCCUCUAAACGGGUCUUGAGGGGUUUU } \\
\text { UU }\end{array}$ \\
\hline RNA 2-1 & $\begin{array}{l}\text { GGGGAACUCGAGACAUAUGUUUCACUUCGGAGUUGCGAAAAUUUGAGA } \\
\text { GACUCACGACGAACUUUCGUUGUUCAGUGUUUCAAUUUUCAGCUUGAU } \\
\text { CCAGAUUUUUACAAAUACUAGUUUGCCAUGUGUAUGUGGGAGACGGUC } \\
\text { GGGUCCAGAUAUUCGUAUCUGUCGAGUAGAGUGUGGGCUCCCACAUAC } \\
\text { UCUGAUGAUCCUUCGGGAUCAUUCAUGGCAACAUAUGCCGCUGAGCAA } \\
\text { UAACUAGCAUAACCCCUUGGGGCCUCUAAACGGGUCUUGAGGGGUUUU } \\
\text { UU }\end{array}$ \\
\hline RNA 3-1 & $\begin{array}{l}\text { GGGGAACUCGAGACAUCUCAGUUGAAGUGGUCUAUACGACAGAGUCAA } \\
\text { UGAGCAAAGGUAUUAACUUUACUCCCUUCAUACCGUGCACCUACCAAA } \\
\text { UCUCCUUAGUGUAAGUACUAGUUUGCCAUGUGUAUGUGGGAGACGGUC } \\
\text { GGGUCCAGAUAUUCGUAUCUGUCGAGUAGAGUGUGGGCUCCCACAUAC } \\
\text { UCUGAUGAUCCUUCGGGAUCAUUCAUGGCAACAUAUGCCGCUGAGCAA } \\
\text { UAACUAGCAUAACCCCUUGGGGCCUCUAAACGGGUCUUGAGGGGUUUU } \\
\text { UU }\end{array}$ \\
\hline RNA 4-1 & $\begin{array}{l}\text { GGGGAACUCGAGCUUCGAAGGGACUUUAUACUAGACGACAUCUGAUUG } \\
\text { GCCCAGGAAGUGAGCAGGCUCAUGGCUCCAGCCGCGGGUCAUAGUUGC } \\
\text { CUCUCUCGCAUGUGAAACUAGUUUGCCAUGUGUAUGUGGGAGACGGUC } \\
\text { GGGUCCAGAUAUUCGUAUCUGUCGAGUAGAGUGUGGGCUCCCACAUAC } \\
\text { UCUGAUGAUCCUUCGGGAUCAUUCAUGGCAACAUAUGCCGCUGAGCAA } \\
\text { UAACUAGCAUAACCCCUUGGGGCCUCUAAACGGGUCUUGAGGGGUUUU } \\
\text { UU }\end{array}$ \\
\hline RNA 2-2 & $\begin{array}{l}\text { GGGGAACUCGAGACAUAUGUUUCACUUCGGAGUUGCGAAAAUUUGAGA } \\
\text { GACUCACGACGAACUUUCGUUGUUCAGUGUUUCAAUUUUCAGCUUGAU } \\
\text { CCAGAUUUUUACAAAUACUAGUAUUUUAACAGCAGAGGACGCAUGCCC } \\
\text { UAUGCGAAAAGUUAACCGUUAGCUGUCGGCUUCGUCCUAUGGCCGUCG } \\
\text { UCCGCUCCGAACUUUAUCCACAUGCCAAAUGCAUAUGCCGCUGAGCAA } \\
\text { UAACUAGCAUAACCCCUUGGGGCCUCUAAACGGGUCUUGAGGGGUUUU } \\
\text { UU }\end{array}$ \\
\hline
\end{tabular}

Table S1 continues on the next page. 
Table S1 (continued from the previous page)

\begin{tabular}{|c|c|}
\hline Name & Nucleotide sequence $\left(5^{\prime} \rightarrow 3^{\prime}\right)^{\mathrm{a}}$ \\
\hline RNA 3-2 & $\begin{array}{l}\text { GGGGAACUCGAGACAUCUCAGUUGAAGUGGUCUAUACGACAGAGUCAA } \\
\text { UGAGCAAAGGUAUUAACUUUACUCCCUUCAUACCGUGCACCUACCAAA } \\
\text { UCUCCUUAGUGUAAGUACUAGUAUUUUAACAGCAGAGGACGCAUGCCC } \\
\text { UAUGCGAAAAGUUAACCGUUAGCUGUCGGCUUCGUCCUAUGGCCGUCG } \\
\text { UCCGCUCCGAACUUUAUCCACAUGCCAAAUGCAUAUGCCGCUGAGCAA } \\
\text { UAACUAGCAUAACCCCUUGGGGCCUCUAAACGGGUCUUGAGGGGUUUU } \\
\text { UU }\end{array}$ \\
\hline RNA 4-2 & $\begin{array}{l}\text { GGGGAACUCGAGCUUCGAAGGGACUUUAUACUAGACGACAUCUGAUUG } \\
\text { GCCCAGGAAGUGAGCAGGCUCAUGGCUCCAGCCGCGGGUCAUAGUUGC } \\
\text { CUCUCUCGCAUGUGAAACUAGUAUUUUAACAGCA GAGGACGCAUGCCC } \\
\text { UAUGCGAAAAGUUAACCGUUAGCUGUCGGCUUCGUCCUAUGGCCGUCG } \\
\text { UCCGCUCCGAACUUUAUCCACAUGCCAAAUGCAUAUGCCGCUGAGCAA } \\
\text { UAACUAGCAUAACCCCUUGGGGCCUCUAAACGGGUCUUGAGGGGUUUU } \\
\text { UU }\end{array}$ \\
\hline RNA 5 & $\begin{array}{l}\text { GGGGAACUCGAGGGAGGAGCCCGCCCAGUCAAACUACCCACCAGACAC } \\
\text { UGUCCGCAACCCGGAUCACGGGUCCACGUUAGAACAUCAAACAUUAAA } \\
\text { GGGUGGUAUUUCAAGGUCGGCUCCAUGCAGACUGGCGUCCACACUUCU } \\
\text { AAGCCUCCCACCUAUCCUACACAUCAAGGCUCAAUGUUCAGUGUCAAG } \\
\text { CACUAGUAUUUUAACAGCAGAGGACGCAUGCCAUAUGCCGCUGAGCAA } \\
\text { UAACUAGCAUAACCCCUUGGGGCCUCUAAACGGGUCUUGAGGGGUUUU } \\
\text { UU }\end{array}$ \\
\hline
\end{tabular}

${ }^{a}$ The first number in the RNA names indicates the identity of the ASR (blue sequence) that begins at nucleotide 7. Sequence regions derived from E. coli are underlined. RNA names with the number 1 following the dash have the Broccoli-F30 aptamer (green sequence). The number 2 following the dash in the RNA names indicates the presence of ASR 6 (pink sequence). RNA 5 lacks both the Broccoli-F30 and ASR 6 sequences due to the length of ASR 5. 
Table S2. Primers used in this study.

\begin{tabular}{ccll}
\hline Primer's name & \multicolumn{1}{c}{ Sequence $\left(5^{\prime} \rightarrow 3^{\prime}\right)$} & \multicolumn{1}{c}{ Purpose } \\
\hline FJN-RNA-1 & GGGGAACTCGAGTACACAAAAATGCAC & $\begin{array}{l}\text { Forward primer for amplification of } \\
\text { reporter RNA 1-1 }\end{array}$ \\
FJN-RNA-2 & GGGGAACTCGAGACATATGTTTCACTT & $\begin{array}{l}\text { Forward primer amplification of } \\
\text { reporter RNA 2-1 and 2-2 }\end{array}$ \\
FJN-RNA-3 & GGGGAACTCGAGACATCTCAGT & $\begin{array}{l}\text { Forward primer for amplification of } \\
\text { reporter RNA 3-1 and 3-2 }\end{array}$ \\
FJN-RNA-4 & GGGGAACTCGAGCTTCGAAG & $\begin{array}{l}\text { Forward primer for amplification of } \\
\text { reporter RNA 4-1 and 4-2 }\end{array}$ \\
FJN-RNA-5 & GGGGAACTCGAGGGAGGAGC & $\begin{array}{l}\text { Forward primer for amplification of } \\
\text { reporter RNA 5 }\end{array}$ \\
T7 reverse & GCTAGTTATTGCTCAGCGGCA & $\begin{array}{l}\text { Reverse primer for amplification of } \\
\text { all reporter RNAs }\end{array}$ \\
& & Forward primer for amplification of \\
FJN-IVT & CAATAAAGCCATCACGAGTACAGC & $\begin{array}{l}\text { DNA templates for } \text { in vitro } \\
\text { transcription of all reporter RNAs }\end{array}$ \\
& & $\begin{array}{l}\text { Reverse primer for amplification of } \\
\text { DNA templates for in vitro } \\
\text { transcription of all reporter RNAs }\end{array}$ \\
\hline JiNian 3'-end & AAAAAACCCCTCAAGACCCGT &
\end{tabular}


Table S3. RNA content of purified AaLS-pos capsids after co-production with reporter RNAs.

\begin{tabular}{ccc}
\hline Reporter RNA & $\mathrm{A}_{260 \mathrm{~nm}} / \mathrm{A}_{280 \mathrm{~nm}}$ & $\begin{array}{c}\text { RNA: protein mass ratio } \\
(\mu \mathrm{g} \text { total RNA/mg AaLS-pos) }\end{array}$ \\
\hline none & $1.27 \pm 0.02$ & $58.4 \pm 3.3$ \\
RNA 1-1 & $1.32 \pm 0.02$ & $66.3 \pm 3.1$ \\
RNA 2-1 & $1.30 \pm 0.01$ & $62.3 \pm 1.7$ \\
RNA 3-1 & $1.35 \pm 0.01$ & $73.2 \pm 2.5$ \\
RNA 4-1 & $1.29 \pm 0.01$ & $60.5 \pm 2.6$ \\
RNA 2-2 & $1.38 \pm 0.03$ & $78.4 \pm 6.0$ \\
RNA 3-2 & $1.35 \pm 0.03$ & $73.6 \pm 7.3$ \\
RNA 4-2 & $1.35 \pm 0.01$ & $72.3 \pm 2.3$ \\
RNA 5 & $1.28 \pm 0.01$ & $60.2 \pm 2.5$ \\
\hline
\end{tabular}


Table S4. The calculated folding free energies of the predicted secondary structures for components of the reporter RNAs.

\begin{tabular}{ccc}
\hline Sequence & \# of nucleotides & $\Delta \mathrm{G}_{\text {fold }}(\mathrm{kcal} / \mathrm{mol})^{\mathrm{a}}$ \\
\hline ASR 1 & 112 & -35 \\
ASR 2 & 112 & -30 \\
ASR 3 & 112 & -19 \\
ASR 4 & 112 & -24 \\
ASR 5 & 217 & -49 \\
Broccoli-F30 & 105 & -49 \\
ASR 6 & 105 & -21 \\
\hline
\end{tabular}

${ }^{\mathrm{a}}$ Calculations of RNA folding free energies $\left(\Delta \mathrm{G}_{\text {fold }}\right)$ were made using the mfold web server (http://unafold.rna.albany.edu/?q=mfold). ${ }^{l}$ 


\section{Supplementary Materials and Methods}

Materials. $\mathrm{Ca}^{2+}$-competent E. coli strain BL21(DE3) was purchased from Transgen Biotech company (Beijing, China). LB broth was purchased from BD company (New York, U.S.A.). LB agar was obtained from Sangon Biotechnology (Shanghai, China). Ampicillin, chloramphenicol, isopropyl $\beta$-D-thiogalactoside (IPTG), lysozyme, DNase I, and RNase A were from Solarbio (Beijing, China). $\mathrm{MgCl}_{2}$ was purchased from Yuanli Huagong (Tianjin, China). $\mathrm{Na}_{2} \mathrm{HPO}_{4} \cdot 12 \mathrm{H}_{2} \mathrm{O}$ and ethylenediaminetetraacetic acid disodium salt (EDTA·2Na) were purchased from Kemiou Chemical Reagent Company (Tianjin, China). $\mathrm{NaH}_{2} \mathrm{PO}_{4} \cdot 2 \mathrm{H}_{2} \mathrm{O}$ was purchased from Damao Chemical Reagent Company (Tianjin, China). Imidazole was purchased from Dibai Biotechnology (Shanghai, China). $\mathrm{NaCl}$ was obtained from BBI Life Science (Shanghai, China). Coomassie Brilliant Blue and TIANquick Midi Purification Kit were purchased from Tiangen (Beijing, China). TRI Reagent was from Molecular Research Center (U.S.A.). Isopropanol and chloroform were purchased from Jiangtian Company (Tianjin, China). RQ1 RNase-free DNase I was purchased from Promega (U.S.A.). HiFiScript cDNA Synthesis Kit and UltraSYBR Mixture (Low ROX) were purchased from Cwbiotech (Tianjin, China). 2×TSINGKE Master Mix and Golden Star T6 Super Mix were from TsingKe biotechnology (Beijing, China). Agarose and Super GelRed were obtained from Yuheng Biotech (Suzhou, China). 100 bp DNA ladder was purchased from TsingKe biotechnology (Beijing, China). DFHBI-1T was purchased from Lucerna (U.S.A.). HiScribe T7 High Yield RNA Synthesis Kit and Monarch RNA Cleanup Kit were purchased from New England Biolabs (U.S.A.). Oligonucleotides were synthesized by Tongyong Technology (Anhui, China) and Synbio Technology (Suzhou, China). 
Sequence design and plasmid construction. To provide sequence diversity in the panel of reporter RNAs, six segments of RNA were designed, which we call arbitrary sequence regions (ASRs). ASRs 1-4 are each 112 nucleotides longs. The first six and last six nucleotides (at the $5^{\prime}$ - and $3^{\prime}$ - ends, respectively) correspond to restriction sites in the encoding DNA (XhoI and SpeI, respectively). The intervening 100 nucleotides each involve some combination of sequence derived from the E. coli genome (which are underlined in Table S1) and randomly generated sequence. For ASR 1, the E. coliderived sequence is 100 nucleotides long and corresponds to a part of the 23S rRNA. ASR 2, has 91 nucleotides of $E$. coli-derived sequence (corresponding to a region upstream of the 23S rRNA) and nine nucleotides of randomly generated sequence. ASR 3 has 35 nucleotides of E. coli derived sequence (corresponding to the reverse complement of a part of the $16 \mathrm{~S}$ rRNA) and 65 nucleotides of randomly generated sequence. ASR 4 contains 100 nucleotides of randomly generated sequence. The combinations of $E$. coliderived and randomly generated sequence result in these ASRs spanning a range of 16 $\mathrm{kcal} / \mathrm{mol}$ in their predicted secondary structural stabilities with steps of $5-6 \mathrm{kcal} / \mathrm{mol}$ (Table S4). ASR 5 is 217 nucleotides long. The $5^{\prime}$ - and $3^{\prime}$ - ends of ASR 5 correspond to XhoI and NdeI sites, respectively, in the encoding DNA. ASR 5 also contains 181 nucleotides of $E$. coli-derived sequence (corresponding to a fragment of the reverse complement of the 23S rRNA) and 24 nucleotides of randomly generated sequence. ASR 6 consists of 105 nucleotides of randomly generated sequence. The Broccoli-F30 aptamer, ${ }^{2}$ which is also 105 nucleotides long, acted as another sequence segment in some of the reporter RNAs in the panel. 
Plasmids pACYC-RNA-1-1, pACYC-RNA-2-1, pACYC-RNA-3-1, pACYC-RNA-41, pACYC-RNA-2-2, pACYC-RNA-3-2, pACYC-RNA-4-2, and pACYC-RNA-5 were constructed to encode a series of 290-nucleotide-long reporter RNAs (Table S1). Briefly, custom-synthesized DNA cassettes (Tongyong Technology and Synbio Technology, China) encoding the various reporter RNAs were inserted into plasmid pACYC-JiNian240. The plasmid pACYC-JiNian-240 was derived from plasmid pACYC-GFP ${ }^{3}$ by inserting a custom-synthesized DNA cassette in between the BgIII sites. In the parent plasmid, this region contains the $\mathrm{T} 7$ promoter, ribosome-binding site, gene encoding GFP, and T7 terminator. In pACYC-JiNian240, this region was replaced with a cassette consisting of (in the $5^{\prime}$ to $3^{\prime}$ direction of the reporter RNA coding strand) a $522 \mathrm{bp}$ sequence immediately downstream of the first BglII site that exactly corresponds to the sequence found in pACYC-GFP, followed by the $6 \mathrm{bp}$ SacI site, the T7 promoter sequence (23 bp), the $6 \mathrm{bp}$ XhoI site, $50 \mathrm{bp}$ of arbitrary (randomly chosen) sequence, the 6 bp SpeI site, the Broccoli-F30 aptamer sequence (105 bp), the 6 bp NdeI site, the T7 reverse primer annealing site and T7 terminator sequence (62 bp), the $6 \mathrm{bp} \mathrm{KpnI} \mathrm{site,} \mathrm{and}$ a $28 \mathrm{bp}$ sequence which exactly matches that found immediately upstream of the second BglII site in pACYC-GFP. For the four plasmids (pACYC-RNA-1-1, pACYC-RNA-2-1, pACYC-RNA-3-1 and pACYC-RNA-4-1) encoding reporter RNAs with the BroccoliF30 aptamer, 100 bp cassettes corresponding to ASRs 1-4 were inserted in between the XhoI and SpeI sites of pACYC-JiNian240. For three of the plasmids (pACYC-RNA-2-2, pACYC-RNA-3-2 and pACYC-RNA-4-2) encoding reporter RNAs without the Broccoli-F30 aptamer, the 105 bp sequence corresponding to ASR 6 (Figure 1) was inserted in between the SpeI and NdeI sites of pACYC-RNA-2-1, pACYC-RNA-3-1 and 
pACYC-RNA-4-1, respectively. To generate plasmid pACYC-RNA-5, a 211 bp cassette was inserted into pACYC-JiNian-240, in between the XhoI and NdeI sites. For each plasmid, the region encoding reporter RNA was verified by DNA sequencing (TsingKe Biotech Company, China).

Bacterial co-production of AaLS-pos capsid and reporter RNAs. Bacterial coproduction of the reporter RNAs with AaLS-pos was carried out using a method similar to that for the co-production of AaLS with protein guests. ${ }^{4}$ The plasmid encoding the capsid protein, pMG-AaLS-pos, ${ }^{5}$ and the plasmid encoding a reporter RNA were cotransformed into $\mathrm{Ca}^{2+}$-competent $E$. coli strain BL21(DE3) by heat shock at $42{ }^{\circ} \mathrm{C}$. The cells were then grown on an LB-agar plate containing ampicillin $(100 \mu \mathrm{g} / \mathrm{mL})$ and chloramphenicol $(30 \mu \mathrm{g} / \mathrm{mL})$ for $16-19 \mathrm{~h}$ at $37^{\circ} \mathrm{C}$. A single colony was transferred to sterile LB medium $(5 \mathrm{~mL})$ containing ampicillin $(100 \mu \mathrm{g} / \mathrm{mL})$ and chloramphenicol $(30 \mu \mathrm{g} / \mathrm{mL})$ and grown for $17-18 \mathrm{~h}$ at $37^{\circ} \mathrm{C}$ and $220 \mathrm{rpm}$. This overnight culture $(1 \mathrm{~mL})$ was used to inoculate sterile $\mathrm{LB}$ media $(500 \mathrm{~mL})$ containing ampicillin $(100 \mu \mathrm{g} / \mathrm{mL})$ and chloramphenicol $(30 \mu \mathrm{g} / \mathrm{mL})$. This new culture was then incubated at $37^{\circ} \mathrm{C}$ and $220 \mathrm{rpm}$. When the O.D.600 reached 0.6-0.9, IPTG was added to a final concentration of $0.1 \mathrm{mM}$ (to induce overproduction of both reporter RNA and AaLS-pos protein), and the culture was incubated for an additional $12 \mathrm{~h}$ at $30^{\circ} \mathrm{C}$ and $220 \mathrm{rpm}$. The cells were then harvested by centrifugation $\left(8000 \times g, 15 \mathrm{~min}, 4^{\circ} \mathrm{C}\right)$, resuspended in $\sim 30 \mathrm{~mL}$ of residual growth media, transferred to a $50 \mathrm{~mL}$ centrifuge tube, and spun in the centrifuge again $(8000 \times g$, 10 min, $4{ }^{\circ} \mathrm{C}$ ). The cell pellet was then immediately stored at $-20{ }^{\circ} \mathrm{C}$.

Protein Purification. AaLS-pos capsids were purified essentially as described. ${ }^{5} \mathrm{Ni}^{2+}-$ affinity chromatography was carried out using a HiPrep IMAC FF 16/10 column attached 
to an ÄKTA FPLC system (GE Healthcare). Before loading, the affinity column was equilibrated with lysis buffer (50 mM sodium phosphate, $300 \mathrm{mM} \mathrm{NaCl}$, pH 8.0). After injecting the cleared cell lysate, the column was washed with lysis buffer (40 mL) to remove unbound proteins. AaLS-pos was eluted using a linear gradient of lysis buffer containing $500 \mathrm{mM}$ imidazole, from 0-100\%, over $100 \mathrm{~mL}$, followed by an additional 40 $\mathrm{mL}$ of lysis buffer containing $500 \mathrm{mM}$ imidazole. Fractions containing AaLS-pos were identified by SDS-PAGE, pooled, and then concentrated to $2 \mathrm{~mL}$ using a spin concentrator (Sartorius VIVASPIN 20, 30000 MWCO PES) at $4000 \times g$ and $4{ }^{\circ} \mathrm{C}$. The concentrated protein sample was then passed through a $0.22 \mu \mathrm{m}$ filter, and AaLS-pos capsids were further purified by size-exclusion chromatography using a Sephacryl S400HR 16/60 column connected to an ÄKTA FPLC system, as described. Fractions corresponding to the 60 -subunit capsid were pooled, subjected to centrifugation in a spin concentrator (Sartorius VIVASPIN 20, 30000 MWCO PES) at $4000 \times g$ and $4{ }^{\circ} \mathrm{C}$ to a final volume of $\sim 2 \mathrm{~mL}$, and stored at $-20{ }^{\circ} \mathrm{C}$. The purity of protein was confirmed by SDSPAGE. The concentration of purified AaLS-pos capsids was estimated by Bradford assay. The yield of most of co-produced proteins was typically 20-30 mg per L of cell culture.

RNA extraction. RNA was extracted from either purified AaLS-pos capsid samples or whole cell samples using TRI Reagent according to the manufacturer's instructions. Briefly, TRI Reagent $(1 \mathrm{~mL})$ was added to either purified AaLS-pos $(200 \mu \mathrm{L}$ of a $11-27 \mathrm{mg} / \mathrm{mL}$ stock solution) or cell suspension (200 $\mu \mathrm{L}$ of cells in PBS buffer with O.D.600 100) and mixed by repetitive pipetting. The homogenate was incubated at room temperature for $5 \mathrm{~min}$. Chloroform $(200 \mu \mathrm{L})$ was then added to the homogenate, and the 
sample was then shaken with a vortex mixer for $15 \mathrm{~s}$. The mixture was incubated at room temperature for $5 \mathrm{~min}$ and then centrifuged at $12000 \times g$ for $15 \mathrm{~min}$ at $4{ }^{\circ} \mathrm{C}$. The aqueous phase (around $600 \mu \mathrm{L}, \sim 60 \%$ of the volume of TRI Reagent) was carefully transferred into a new tube. Isopropanol $(500 \mu \mathrm{L})$ was added into the aqueous phase to induce RNA precipitation. The mixture was stored at room temperature for $5 \mathrm{~min}$ and centrifuged at $12000 \times g$ for 8 min at $4{ }^{\circ} \mathrm{C}$. The supernatant was discarded, and the RNA precipitate was washed by vortexing with $75 \%$ ethanol $(1 \mathrm{~mL})$ followed by centrifugation at $12000 \times g$ for 5 min. Ethanol was removed using a pipette, and the RNA was air-dried for $5 \mathrm{~min}$ at room temperature. Finally, the RNA was dissolved in DEPC-treated water and stored at $-80^{\circ} \mathrm{C}$. The concentration of RNA was estimated by measuring the $\mathrm{A}_{260 \mathrm{~nm}}$ using a Nano-drop microvolume spectrophotometer (TECAN Infinite M200 Pro plate reader, Switzerland). The quality of RNA was assessed by the ratio of $\mathrm{A}_{260 \mathrm{~nm}}$ to $\mathrm{A}_{280 \mathrm{~nm}}$ and the ratio of $A_{260 \mathrm{~nm}}$ to $\mathrm{A}_{230 \mathrm{~nm}}$.

Qualitative RT-PCR and agarose gel electrophoresis. The presence of the reporter RNAs in extracts of either purified AaLS-pos capsids or whole cells was confirmed by reverse-transcription PCRs (RT-PCR) and agarose gel electrophoresis. Before synthesis of cDNA, RNA samples were pre-treated by RQ1 RNase-free DNase I to remove any possible DNA contamination. For DNase I treatment of each RNA extract, 2 U DNase was added to a mixture containing RNA $(2 \mu \mathrm{g}), 5 \times \mathrm{RT}$ Buffer $(2 \mu \mathrm{L})$, and RNase-free water. The total volume of the sample was $10 \mu \mathrm{L}$. After centrifugation for several seconds, the mixture was incubated at $37{ }^{\circ} \mathrm{C}$ for $30 \mathrm{~min}$, followed by incubation at $65^{\circ} \mathrm{C}$ for 10 min to inactivate the DNase I. Reverse transcription was performed using the HiFiScript cDNA synthesis kit and following the manufacturer's instructions. In a $20 \mu \mathrm{L}$ 
reaction system, the sample contained $4 \mu \mathrm{L}$ of dNTP Mix (stock solution containing all four standard deoxynucleotides, $2.5 \mathrm{mM}$ each), $2 \mu \mathrm{L}$ of $\mathrm{T} 7$ reverse primer $(10 \mu \mathrm{M}$ stock solution in RNase-free water), $2 \mu \mathrm{L}$ of DNase-treated RNA template (200 ng/ $\mu \mathrm{L}$ stock solution), $4 \mu \mathrm{L}$ of $5 \times \mathrm{RT}$ Buffer, $2 \mu \mathrm{L}$ of DTT (0.1 M stock solution), $1 \mu \mathrm{L}$ of HiFiScript (200 U/ $\mu \mathrm{L}$ stock solution), and RNase-free water ( $5 \mu \mathrm{L})$. A control omitting the reverse transcriptase was carried out for each RNA sample. Following centrifugation for several seconds, the mixture was incubated at $50{ }^{\circ} \mathrm{C}$ for $40 \mathrm{~min}$, followed by incubation at $85^{\circ} \mathrm{C}$ for $5 \mathrm{~min}$ to stop the reaction.

The cDNA was then amplified by PCR, using the appropriate forward primer for each template (Table S2) and the T7 reverse primer. Each PCR was carried out in a total volume of $25 \mu \mathrm{L}$ that contained cDNA $(1 \mu \mathrm{L}), 0.5 \mu \mathrm{L}$ of each primer $(10 \mu \mathrm{M}$ stock solution in water), $12.5 \mu \mathrm{L}$ of $2 \times$ TSINGKE Master Mix, and $\mathrm{ddH}_{2} \mathrm{O}(10.5 \mu \mathrm{L})$. The PCR reaction was conducted using an Eppendorf Mastercycler Nexus PCR machine (Germany). The cycling program was as follows: initial denaturation at $94{ }^{\circ} \mathrm{C}$ for $3 \mathrm{~min}$; followed by 30 cycles of denaturation $\left(94^{\circ} \mathrm{C}\right.$ for $\left.10 \mathrm{~s}\right)$, annealing $\left(62^{\circ} \mathrm{C}\right.$ for $\left.10 \mathrm{~s}\right)$, and extension $\left(72{ }^{\circ} \mathrm{C}\right.$ for $\left.1 \mathrm{~min}\right)$; and a final extension at $72{ }^{\circ} \mathrm{C}$ for $10 \mathrm{~min}$.

The RT-PCR products were analyzed by agarose gel electrophoresis. Each sample (5$10 \mu \mathrm{L})$ was loaded onto a 3\% (v/v) agarose gel containing Super GelRed dye (1×final concentration). The PCR products were resolved by applying $120 \mathrm{~V}$ for $50 \mathrm{~min}$ in $1 \times \mathrm{TAE}$ gel running buffer and detected using a UV transilluminator.

In vitro transcription. Pure standards of each reporter RNA were synthesized by in vitro transcription. PCR products corresponding to a region of each plasmid (pACYC-RNA 1-1, pACYC-RNA 2-1, pACYC-RNA 3-1, pACYC-RNA 4-1, and 
pACYC-RNA 5) containing the T7 promoter and RNA-coding portions were used as templates for RNA synthesis. These plasmid fragments were amplified by PCR using a forward primer upstream of the $\mathrm{T} 7$ promoter, FJN-IVT, and a reverse primer that anneals to the last 21 nucleotides of the T7 terminator, JiNian-3'-end (Table S2). In each PCR, the appropriate plasmid (30 ng) was mixed with $2 \mu \mathrm{L}$ of the forward primer FJN-IVT $(10 \mu \mathrm{M}$ stock solution in water), $2 \mu \mathrm{L}$ of reverse primer JiNian-3'-end (10 $\mu \mathrm{M}$ stock solution in water), $45 \mu \mathrm{L}$ of Golden Star T6 super Mix, and $\mathrm{ddH}_{2} \mathrm{O}$. The PCR reaction was conducted using an Eppendorf Mastercycler Nexus PCR machine. The cycling program was as follows: initial denaturation at $98^{\circ} \mathrm{C}$ for $2 \mathrm{~min}$, followed by 30 cycles of $10 \mathrm{~s}$ at $98{ }^{\circ} \mathrm{C}, 10 \mathrm{~s}$ at $60{ }^{\circ} \mathrm{C}$, and $10 \mathrm{~s}$ at $72{ }^{\circ} \mathrm{C}$. The final extension was at $72{ }^{\circ} \mathrm{C}$ for $1 \mathrm{~min}$. The PCR products were then purified using a TIANquick Midi Purification Kit by following the manufacturer's instructions. The purity of PCR templates was evaluated by agarose gel electrophoresis. The concentration of PCR templates was estimated by measuring the A260 nm with a Nano-drop microvolume spectrophotometer.

In vitro transcription was carried out with a HiScribe T7 High Yield RNA Synthesis Kit by following the manufacturer's instructions. The resulting transcripts were purified using a Monarch RNA Cleanup Kit by following the manufacturer's instructions. The concentration of RNAs was estimated by measuring the $\mathrm{A}_{260 \mathrm{~nm}}$ with a Nano-drop microvolume spectrophotometer. The quality of each RNA sample was assessed by the ratio of $A_{260 \mathrm{~nm}}$ to $A_{280 \mathrm{~nm}}$ and the ratio of $A_{260 \mathrm{~nm}}$ to $A_{230 \mathrm{~nm}}$. All of the transcripts had good purity.

Quantitative RT-PCR. Following in vitro transcription, each reporter RNA was used to construct standard curves for q-RT-PCR analysis. The DNase I treatment of each RNA 
sample was the same as above. Serial dilutions of each DNase I-treated RNA were made. Reverse transcription was performed using the HiFiScript cDNA synthesis kit and following the manufacturer's instructions for each diluted sample. In a $20 \mu \mathrm{L}$ reaction system, the sample contained $4 \mu \mathrm{L}$ of dNTP Mix (stock solution containing all four standard deoxynucleotides, $2.5 \mathrm{mM}$ each), $2 \mu \mathrm{L}$ of $\mathrm{T} 7$ reverse primer (10 $\mu \mathrm{M}$ stock solution in RNase-free water), $5 \mu \mathrm{L}$ of DNase I-treated RNA template (varying concentrations), $4 \mu \mathrm{L}$ of $5 \times \mathrm{RT}$ Buffer, $2 \mu \mathrm{L}$ of DTT (0.1 M stock solution), $1 \mu \mathrm{L}$ of HiFiScript (200 U/ $\mu \mathrm{L}$ stock solution), and RNase-free water $(2 \mu \mathrm{L})$. Following centrifugation for several seconds, the mixture was incubated at $50{ }^{\circ} \mathrm{C}$ for $15 \mathrm{~min}$, followed by incubation at $85^{\circ} \mathrm{C}$ for 5 min to stop the reaction.

Each cDNA was used as the template for q-PCR. The cDNA $(6.5 \mu \mathrm{L})$ was mixed with $0.5 \mu \mathrm{L}$ of the corresponding forward primer (10 $\mu \mathrm{M}$ stock solution in water) (Table $\mathrm{S} 2)$, $0.5 \mu \mathrm{L}$ of the $\mathrm{T} 7$ reverse primer $(10 \mu \mathrm{M}$ stock solution in water), and $7.5 \mu \mathrm{L}$ of 2xUltraSYBR Mixture (low ROX). PCR thermocycling consisted of a 10 min hot start at $95^{\circ} \mathrm{C}$, followed by 40 amplification cycles of $95^{\circ} \mathrm{C}$ for $15 \mathrm{~s}$ and $62^{\circ} \mathrm{C}$ for $1 \mathrm{~min}$, and a melting curve stage of $95^{\circ} \mathrm{C}$ for $15 \mathrm{~s}, 60^{\circ} \mathrm{C}$ for $1 \mathrm{~min}, 95^{\circ} \mathrm{C}$ for $15 \mathrm{~s}$, and $60{ }^{\circ} \mathrm{C}$ for $15 \mathrm{~s}$. The identity and purity of the q-PCR products was confirmed by agarose gel electrophoresis. Standard curves for each of the five DNA sequences encoding the reporter RNAs were obtained by fitting a plot of the $C_{t}$ values versus $\log$ [RNA template] to a linear equation. These standard curves were used to estimate the absolute amount of reporter RNA in each extract, based on their $C_{t}$ values.

RNA extracts from purified AaLS-pos capsid samples and whole cell samples were also used as templates for q-RT-PCR, in order to measure the level of reporter RNA 
present in each extract. The procedures were essentially the same as for the in vitro transcribed RNAs, except for two minor differences. First, the amount of RNA template used for reverse transcription was $1 \mu \mathrm{g}(5 \mu \mathrm{L}$ of a $200 \mathrm{ng} / \mu \mathrm{L}$ stock solution). Second, the cDNA was diluted 100-fold with RNase-free water before adding $6.5 \mu \mathrm{L}$ of the diluted cDNA to the q-PCR mixture. The $\mathrm{C}_{\mathrm{t}}$ values were measured in triplicate for each RNA extract and were used to estimate the reporter RNA level according to the appropriate standard curve. For each reporter RNA, q-RT-PCR analysis was carried out using RNA extracts derived from three independent cultures (RNA and AaLS-pos co-production batches).

Fluorescence spectroscopy. The relationship between DFHBI-1T fluorescence and reporter RNA concentration was analyzed using in vitro transcribed RNAs that possessed the Broccoli-F30 aptamer. Each sample analyzed by fluorescence spectroscopy contained reporter RNA standard (varying amounts), $14.5 \mu \mathrm{L}$ of $10 \times \mathrm{PBS}$ (nuclease-free), $5 \mu \mathrm{L}$ of $\mathrm{MgCl}_{2}$ (8 mM stock solution in RNase-free water), $50 \mu \mathrm{L}$ of DFHBI-1T (400 $\mu \mathrm{M}$ stock solution in $1 \times \mathrm{PBS}$ ), and DEPC-treated water. The total volume of one sample was $200 \mu \mathrm{L}$. The fluorescence emission at $505 \mathrm{~nm}$ was recorded after excitation at $460 \mathrm{~nm}$. The observed fluorescence intensities were normalized and then corrected by subtracting out the normalized background signal of a control sample lacking any RNA. Standard curves for each in vitro transcribed reporter RNA were constructed by fitting a plot of the fluorescence intensity versus the mass of reporter RNA to a linear equation.

RNA extracts were also analyzed according to their influence on DFHBI-1T fluorescence. Measurements of fluorescence intensity were made the same way as above, except for the amount of RNA extract added to each sample $(104 \mu \mathrm{g}$, for RNA extracted 
from purified AaLS-pos capsids, or $200 \mu \mathrm{g}$, for RNA extracted from whole cell samples).

The observed fluorescence intensities were normalized and then corrected by subtracting out the normalized background signal of a control sample extracted either from purified AaLS-pos capsids that were produced in the absence of any reporter RNA or from whole cells that contained AaLS-pos produced in the absence of any reporter RNA. The absolute amount of reporter RNA in each sample was calculated according to the appropriate standard curve. For each reporter RNA, fluorescence analysis was carried out in triplicate, using RNA extracts derived from independent cultures (RNA and AaLS-pos co-production batches).

\section{References}

[1] Zuker, M. (2003) Mfold web server for nucleic acid folding and hybridization prediction, Nucleic Acids Res. 31, 3406-3415.

[2] Filonov, G. S., Kam, C. W., Song, W., and Jaffrey, S. R. (2015) In-gel imaging of RNA processing using Broccoli reveals optimal aptamer expression strategies, Chem. Biol. 22, 649-660.

[3] Seebeck, F. P., Woycechowsky, K. J., Zhuang, W., Rabe, J. P., and Hilvert, D. (2006) A simple tagging system for protein encapsulation, J. Am. Chem. Soc. 128, 45164517.

[4] Han, X., and Woycechowsky, K. J. (2017) Encapsulation and controlled release of protein guests by the Bacillus subtilis lumazine synthese capsid, Biochemistry 56, 6211-6220.

[5] Lilavivat, S., Sardar, D., Jana, S., Thomas, G. C., and Woycechowsky, K. J. (2012) In vivo encapsulation of nucleic acids using an engineered non-viral protein capsid, J. Am. Chem. Soc. 134, 13152-13155. 